\title{
CONTRIBUIÇÃO DA CAATINGA NA SUSTENTABILIDADE DE PROJETOS DE ASSENTAMENTOS NO SERTÃO NORTE-RIO-GRANDENSE ${ }^{1}$
}

\author{
Márcio Rocha Francelino ${ }^{2}$, Elpídio Inácio Fernandes Filho ${ }^{3}$, Mauro Resende ${ }^{4} \mathrm{e}$ \\ Helio Garcia Leite ${ }^{5}$
}

\begin{abstract}
RESUMO - Os objetivos deste trabalho foram caracterizar os recursos florestais da caatinga e determinar a sua contribuição na sustentabilidade em projetos de reforma agrária localizados na região oeste do Estado do Rio Grande do Norte. Foi realizado um levantamento florístico, no qual se constatou que as espécies mais bem distribuídas pelas unidades amostrais foram as de caráter pioneiro, indicando que essas matas já foram exploradas anteriormente à ocupação dos assentados. $\mathrm{O}$ estrato florestal mais comum foi o arbustivo-arbóreo fechado, correspondendo a $75 \%$ da parcelas amostradas. Os assentamentos com presença de cobertura florestal do tipo arbustivo-arbórea aberta apresentaram baixa densidade, associada à baixa diversidade florística e à forte tendência à homogeneização, o que as enquadra como prioritárias em um processo de conservação e, ou, enriquecimento da flora. Devido à baixa rentabilidade da exploração dos recursos florestais da caatinga, essa atividade deveria servir apenas como complemento de renda dos assentados, já que outras atividades apresentam maiores retornos econômicos. Entretanto, ela possui grande importância no contexto social, sendo fundamental para a sustentabilidade dos assentamentos estudados.
\end{abstract}

Palavras-chave: Reforma agrária, preservação e caatinga.

\section{CAATINGA FOREST CONTRIBUTION TO THE SUSTAINABILITY OF SETTLEMENT PROJECTS ON RIO GRANDE DO NORTE BACKWOODS}

\begin{abstract}
A floristic survey was conducted to characterize the caating a forest resources as well as to determine its contribution to the sustainability agrarian reform projects in western Rio Grande do Norte. This survey showed that the pioneer species were better distributed in the sampling units, indicating that these forests had been explored prior to occupation by the settlers. The closed arboreal-shruby type was the most common forest stratum, and corresponded to $75 \%$ of the sampled plots. The settlements with forest cover of the open arboreal-shruby type presented low density associated with a low floristic diversity as well as a marked tendency to homogenization, making this forest cover a priority for conservation and/or flora enrichment. Due to its low profitability, exploration of caatinga forest resources should be only an complement to the settlers' income, since other activities provide higher economic returns. However, the caating forest is very important within a social context, being fundamental for the sustainability of the settlements studied.
\end{abstract}

Key words: Agrarian reform, preservation, caatinga.

1 Recebido para publicação em 14.8.2001.

Aceito para publicação em 19.2.2003.

Parte da tese do primeiro autor, que teve apoio da WWF.

2 Bolsista da CAPES, doutorando em Solos e Nutrição de Plantas na Universidade Federal de Viçosa - UFV; ${ }^{3}$ Professor Adjunto do Departamento de Solos da UFV; ${ }^{4}$ Núcleo de Estudos de Planejamento e Uso da Terra - NEPUT/UFV; ${ }^{5}$ Professor Adjunto do Departamento de Engenharia Florestal da UFV. 


\section{INTRODUÇÃO}

O semi-árido nordestino ocupa uma área de aproximadamente $700.000 \mathrm{~km}^{2}$, com população de 23 milhões de pessoas. Segundo Ab'Saber (1999), nele há “(...) muito mais gente do que as relações de produção ali imperantes podem suportar". Esse adensamento humano, atípico para uma região semi-árida, acentua a debilidade do seu ecossistema, e a locação de projetos de assentamentos (PAs) nessas condições deveria considerar essa fragilidade, exigindo maior preocupação com a escassez dos recursos naturais. Os recursos florestais são, geralmente, os primeiros a ser explorados pelos assentados, assumindo importante papel no contexto econômico e social desses projetos. Seus produtos constituem, além de fonte de energia primária, um importante complemento de renda (PNUD/FAO/ IBAMA, 1993).

A exemplo de outras regiões do País, o Estado do Rio Grande do Norte foi submetido a intenso processo de distribuição de terras nos últimos anos; somente no período de 1995 a 1999 foram criados $81 \%$ de todos seus PAs. Em 1999 eram 153 PAs, assentando 11.308 famílias em uma área de 358.225 ha (INSTITUTO NACIONAL DE COLONIZAÇÃO E REFORMA AGRÁRIA INCRA, 1999), representando cerca de $6,44 \%$ do território do Estado. Diante da falta de investimentos no processo produtivo em muitas dessas áreas, os trabalhadores rurais buscam sua sobrevivência no extrativismo generalizado, o que é intensificado durante as épocas de estiagens prolongadas. É necessário, entretanto, identificar os limites físicos desses ambientes, a fim de garantir a preservação dos recursos e a própria permanência desses colonos nas áreas.

Os objetivos deste trabalho foram caracterizar os recursos florestais do bioma caatinga no sertão norterio-grandense e avaliar sua contribuição na sustentabilidade em dez projetos de reforma agrária localizados na região oeste do Estado do Rio Grande do Norte.

\section{MATERIAL E MÉTODOS}

\section{1. Área de Estudo}

Foram estudados dez PAs localizados na região oeste do Estado do Rio Grande do Norte, os quais, juntos, somam 27.555,16 ha (Quadro 1). Esses projetos estão ocupados principalmente por vegetação do tipo hiperxerófila, caracterizando bem as condições edafoclimáticas das caatingas.

O inventário florestal foi realizado, empregando a metodologia descrita por Carvalho \& Zákia (1994), que consideraram quatro tipos de estratos vegetais na região semi-árida norte-rio-grandense (Quadro 2). O método de amostragem nas áreas que apresentaram diferentes tipos florestais foi o casual estratificado e nas que apresentaram estrato homogêneo, o casual simples. Foram lançadas 44 parcelas do tipo permanente, com $400 \mathrm{~m}^{2}$ de área cada, distribuídas aleatoriamente, cujas coordenadas geográficas foram registradas e as árvores dos quatro cantos

Q uadro 1 - P rojetos de assentam entos selecionados

Table 1 - Selected settlem ent projects

\begin{tabular}{|c|c|c|c|c|c|}
\hline \multirow{2}{*}{ PA } & \multirow{2}{*}{ Localização } & \multirow{2}{*}{ Ano de Criação } & \multirow{2}{*}{ № de Famílias } & Área & Área/Família \\
\hline & & & & \multicolumn{2}{|c|}{ (ha) } \\
\hline Aurora da Serra & Apodi & 97 & 58 & $1.435,4$ & 24,7 \\
\hline Cabelo de Negro & Mossoró & 95 & 96 & $2.821,7$ & 29,4 \\
\hline Canto Comprido & Carnaubais & 95 & 127 & $3.917,8$ & 30,8 \\
\hline Cordão de Sombra & Mossoró & 96 & 117 & $3.997,7$ & 34,2 \\
\hline Esperança & Upanema & 96 & 76 & $2.300,7$ & 30,7 \\
\hline Hipólito & Mossoró & 87 & 137 & $4.840,8$ & 35,3 \\
\hline Lagoa Vermelha & Upanema & 95 & 34 & $1.194,2$ & 35,1 \\
\hline Mulunguzinho & Mossoró & 92 & 112 & $4.000,0$ & 35,7 \\
\hline Recreio & Mossoró & 96 & 73 & $2.047,3$ & 28,0 \\
\hline Soledade & Apodi & 89 & 34 & 999,5 & 29,4 \\
\hline Total & & & 864 & $27.555,1$ & \\
\hline
\end{tabular}

R. Árvore, Viçosa-MG, v.27, n.1, p.79-86, 2003 
Q u adro 2 - T ipos florestais segundo o grau de cobertura do solo Table 2 - F orest types according to the degree of soil cover

\begin{tabular}{|c|c|c|l|}
\hline Tipo Florestal & $\begin{array}{c}\text { Porte Médio } \\
(\mathrm{m})\end{array}$ & \multicolumn{1}{|c|}{ Definição } & \multicolumn{1}{c|}{ Características } \\
\hline 1 & - & - & Agricultura, pastagens ou áreas sem vegetação lenhosa. \\
\hline 2 & 3 & Arbustivo-arbórea aberta & $\begin{array}{l}\text { Baixo índice de cobertura do solo, com ocorrência em } \\
\text { solos rasos, pedregosos ou afloramento rochoso. }\end{array}$ \\
\hline 3 & $3-4$ & Arbustivo-arbórea fechada & $\begin{array}{l}\text { Alto grau de cobertura do solo e maior variabilidade } \\
\text { fisionômica. }\end{array}$ \\
\hline 4 & $4-5$ & Arbórea fechada & Alto grau de cobertura do solo e presença de sub-bosques. \\
\hline
\end{tabular}

Fonte: Carvalho \& Zákia (1994).

foram marcadas a 1,3 $\mathrm{m}$ de altura. A intensidade e a distribuição das parcelas nos PAs foram dependentes do tamanho das respectivas reservas e do tipo florestal presente. Admitiu-se um erro de amostragem de 20 a 95\% de probabilidade, para o volume com casca. Mediramse apenas as árvores com diâmetro a 1,3 m (dap) maior que $1,5 \mathrm{~cm}$, considerando este o diâmetro mínimo utilizado na região para lenha, vara e ripa. As classes de dap e de área basal $(B)$ que foram consideradas estão relacionadas no Quadro 3. Na totalização das parcelas foram utilizadas equações ajustadas em trabalhos desenvolvidos pelo Projeto PNUD/FAO/IBAMA/BRA/87/007. Foi considerado o fator de empilhamento igual a 3,14 (PNUD/FAO/IBAMA, 1993).

Q uadro 3 - C lasses de diâm etro e áreas basais equivalentes utilizadas

Table 3 - D iam eter classes and equivalent basal areas used

\begin{tabular}{|c|c|c|}
\hline \multirow{2}{*}{ Classe } & Diâmetro (dap) & Área Basal \\
\cline { 2 - 3 } & $(\mathrm{cm})$ & $\left(\mathrm{m}^{2}\right)$ \\
\hline I & $1,5-7,5$ & $0,0002-0,0044$ \\
II & $7,5-10,5$ & $0,0044-0,0087$ \\
III & $10,5-12,5$ & $0,0087-0,0123$ \\
IV & $12,5-14,5$ & $0,0123-0,0165$ \\
V & $\geq 14,5$ & $\geq 0,0165$ \\
\hline
\end{tabular}

Fonte: Carvalho \& Zákia (1994).

Para determinar o estoque em função do potencial de uso consideraram-se apenas espécies de possível exploração de estacas, mourões, lenha e carvão, de acordo com informações obtidas dos assentados por meio de entrevistas, utilizando técnicas informais, conforme descrito em Oliveira \& Oliveira (1982).
Os dados das parcelas foram analisados, utilizando formulários da amostragem casual estratificada para $o$ PA Cabelo de Negro, visto que neste foram encontradas duas tipologias (tipos 2 e 3); para os demais PAs que apresentavam estrato homogêneo foi empregada a amostragem casual simples. Os dados dos questionários foram analisados descritivamente. Foram também realizadas simulações do retorno econômico da comercialização de alguns produtos obtidos nos assentamentos.

\section{RESULTADOS E DISCUSSÃO}

\subsection{Totalização do Estoque}

Os resultados das análises estatísticas em relação às tipologias florestais (estratos) estão sumariados no Quadro 4 e para cada um dos PAs, no Quadro 5. As áreas com presença do estrato tipo 2 apresentaram baixa densidade, sendo constituídas predominantemente de árvores da classe I (Quadro 6). Este fato, associado a uma pobre diversidade florística (Quadro 9), enquadra essas áreas como prioritárias em um processo de conservação. Já o estrato florestal mais comum foi o arbustivo-arbóreo fechado, compreendendo $75 \%$ da parcelas lançadas na população (Quadro 7).

$\mathbf{Q}$ u adro 4 - E statísticas obtidas para os tipos florestais Table 4 - Statistics obta ined for the forest types

\begin{tabular}{|l|r|r|r|}
\hline \multicolumn{1}{|c|}{ Estimativa } & Tipo 2 & Tipo 3 & Tipo 4 \\
\hline Volume médio $\left(\mathrm{m}^{3} / \mathrm{ha}\right)$ & 23,08 & 52,60 & 111,18 \\
Área basal $\left(\mathrm{m}^{2} / \mathrm{ha}\right)$ & 3,16 & 7,32 & 17,42 \\
Altura total média $(\mathrm{m})$ & 2,80 & 3,10 & 4,50 \\
Número de árvores/ha (média) & 3.531 & 5.794 & 5.833 \\
Número de parcelas (n) & 8 & 33 & 3 \\
\hline
\end{tabular}


Q u adro 5 - E statísticas obtidas para cada projeto de assentam ento

Table 5 - Statistics obtained for each settlem entproject

\begin{tabular}{|c|c|c|c|c|c|c|}
\hline \multirow{2}{*}{$\begin{array}{c}\text { Projeto de } \\
\text { Assentamento }\end{array}$} & \multirow[t]{2}{*}{$\mathrm{n}^{\underline{1} /}$} & \multirow{2}{*}{$\begin{array}{c}\text { Tipo } \\
\text { Florestal }^{2 /}\end{array}$} & $\begin{array}{l}\text { Altura Total } \\
\text { Média }\end{array}$ & Área Basal & Volume & $\begin{array}{c}\text { Intervalo de Confiança a } \\
95 \% \text { de Probabilidade }\end{array}$ \\
\hline & & & (m) & $\left(\mathrm{m}^{2} / \mathrm{ha}\right)$ & \multicolumn{2}{|r|}{$\left(\mathrm{m}^{3} / \mathrm{ha}\right)$} \\
\hline Aurora da Serra & 4 & 3 & 2,8 & 7,3 & 54,1 & $56,3 \leq \mu \leq 52,0$ \\
\hline Cabelo de Negro & 7 & 3 e 4 & 3,8 & 12,9 & $70,7^{-4}$ & $66,0 \leq \mu \leq 75,5^{5}$ \\
\hline Canto Comprido ${ }^{3 /}$ & 20 & 3 & - & 7,8 & 72,0 & $63,0 \leq \mu \leq 80,9$ \\
\hline Cordão de Sombra & 4 & 3 & 3,1 & 7,0 & 40,4 & $35,2 \leq \mu \leq 45,5$ \\
\hline Esperança & 4 & 2 & 2,6 & 3,3 & 25,1 & $20,2 \leq \mu \leq 30,0$ \\
\hline Hipólito & 4 & 2 & 2,8 & 3,0 & 21,1 & $16,87 \leq \mu \leq 25,24$ \\
\hline Lagoa Vermelha & 6 & 2 & 2,9 & 6,9 & 43,1 & $34,7 \leq \mu \leq 51,3$ \\
\hline Mulunguzinho & 5 & 3 & 3,0 & 6,9 & 57,9 & $45,3 \leq \mu \leq 70,5$ \\
\hline Recreio & 5 & 3 & 3,0 & 7,2 & 56,4 & $45,0 \leq \mu \leq 65,7$ \\
\hline Soledade & 5 & 3 & 3,8 & 7,6 & 50,6 & $40,8 \leq \mu \leq 60,5$ \\
\hline
\end{tabular}

$\underline{1} /=$ número de parcelas. ${ }^{2 /}=$ tipo florestal: 1 = arbustivo-arbóreo aberto, $2=$ arbustivo-arbóreo fechado e $3=$ arbóreo fechado. ${ }^{3 /}=$ fonte: Carvalho (1998). ${ }^{4 /} \mathrm{e}^{\underline{5}}=$ volume médio e intervalo de confiança ponderados pela área.

Q uadro 6 - E stoque por classe de diâm etro para o tipo arbustivo-arbóreo aberto

Table 6 - Stock based on diam eter class for the open arborea l-bush type

\begin{tabular}{|c|c|c|c|c|c|c|}
\hline \multirow{2}{*}{ Classe de Diâmetro } & \multirow{2}{*}{$\begin{array}{c}\text { Densidade } \\
\text { (arv./ha) }\end{array}$} & \multirow{2}{*}{$\begin{array}{c}\text { População } \\
(\%) \\
\end{array}$} & \multirow{2}{*}{$\frac{\text { Área Basal }}{\left(\mathrm{m}^{2} / \mathrm{ha}\right)}$} & \multicolumn{3}{|c|}{ Volume } \\
\hline & & & & $\left(\mathrm{m}^{3} / \mathrm{ha}\right)$ & (st/ha) & $(\%)$ \\
\hline I & 3.450 & 97,70 & 2,46 & 19,92 & 67,73 & 86,31 \\
\hline II & 56 & 1,59 & 0,34 & 1,50 & 5,10 & 6,50 \\
\hline III & 19 & 0,55 & 0,19 & 0,85 & 2,89 & 3,68 \\
\hline IV & 3 & 0,08 & 0,05 & 0,21 & 0,71 & 0,91 \\
\hline $\mathrm{V}$ & 3 & 0,08 & 0,12 & 0,60 & 2,04 & 2,60 \\
\hline Total & 3.531 & 100,00 & 3,16 & 23,08 & 78,47 & 100,00 \\
\hline
\end{tabular}

Q u adro 7 - E stoque geralpor classe de diâm etro para o tipo arbu stivo-arbóreo fechado

Table 7 - G eneral stock for diam eter class for dense a rborea l-bush type

\begin{tabular}{|c|c|c|c|c|c|c|}
\hline \multirow{2}{*}{ Classe de Diâmetro } & \multirow{2}{*}{$\begin{array}{c}\text { Densidade } \\
\text { (arv./ha) }\end{array}$} & \multirow{2}{*}{$\begin{array}{c}\text { População } \\
(\%)\end{array}$} & \multirow{2}{*}{$\frac{\text { Área Basal }}{\left(\mathrm{m}^{2} / \mathrm{ha}\right)}$} & \multicolumn{3}{|c|}{ Volume } \\
\hline & & & & $\left(\mathrm{m}^{3} / \mathrm{ha}\right)$ & (st/ha) & $(\%)$ \\
\hline $\mathrm{I}$ & 5.527 & 95,39 & 4,35 & 35,58 & 120,97 & 67,64 \\
\hline II & 152 & 2,62 & 0,89 & 4,80 & 16,32 & 9,12 \\
\hline III & 48 & 0,83 & 0,50 & 2,57 & 8,74 & 4,89 \\
\hline IV & 30 & 0,52 & 0,44 & 2,61 & 8,87 & 4,97 \\
\hline $\mathrm{V}$ & 37 & 0,64 & 1,14 & 7,04 & 23,94 & 13,38 \\
\hline Total & 5.794 & 100,00 & 7,32 & 52,60 & 178,84 & 100,00 \\
\hline
\end{tabular}

R. Árvore, Viçosa-MG, v.27, n.1, p.79-86, 2003 
O tipo florestal arbóreo fechado só foi encontrado em um dos assentamentos, em uma faixa com cerca de $60 \mathrm{ha}$. As árvores pertencentes à classe diamétrica $\mathrm{V}$, mesmo representando somente $3,70 \%$ da população, contribuem com $28 \%$ do volume total (Quadro 8).

\subsection{Florística}

Foram encontradas 46 espécies de árvores nativas; destas, a aroeira (Myracrodruon urundeuva) está na lista das ameaçadas de extinção, editada pelo INSTITUTO BRASILEIRO DE MEIO AMBIENTE - IBAMA (1991). Ela se encontra bem representada nessas áreas, com freqüência de 31\% (Quadro 9), porém por diversas vezes foi verificado o seu corte, principalmente para confecção de mourões.

As espécies mais bem distribuídas pelas unidades amostrais foram justamente as de caráter pioneiro, como o marmeleiro (Croton hemiargyreus), com freqüência de 93\%, seguido pela catingueira (Caesalpina pyramidalis) e pelo mororó (Bauhinia forficata), com 82 e 75\%, respectivamente, o que indica que essas matas já foram exploradas anteriormente à ocupação dos assentados. Deve-se considerar que essas inferências sobre o comportamento fitossociológico da população são limitadas, uma vez que a metodologia aplicada no inventário foi mais direcionada para determinação de estoques. Das 8.107 árvores mensuradas da classe I, correspondente a $85 \%$ do total, 3.065 são marmeleiros (38\%). Caso preocupante é o das espécies como angico (Anademanthera microcarpa) e aroeira (Myracrodruon urundeuva), em que a quase totalidade de seus indivíduos encontra-se nas classes superiores, não tendo, portanto, representantes na classe de diâmetro I $(1,5-7,5 \mathrm{~cm})$, justamente a que garante a continuidade das espécies na área. Foi observada a presença de árvores de porte arbóreo sobre áreas de lajeados, entremeados por Neossolos Litólicos, o que é conseqüência de maior acúmulo de água, de fósforo e de nitrogênio nos solos existentes entre as placas de calcário.

\subsection{Uso dos Recursos Florestais}

Os recursos florestais da caatinga são fundamentais para a sobrevivência econômica (e social) dos assentamentos, principalmente no caso daqueles que não possuem muitas alternativas de ocupação de mão-deobra.

Os principais meios de utilização não-comerciais dos recursos florestais por parte dos assentados, verificados em campo, podem ser assim resumidos:

a) Fonte energética: o consumo médio de lenha para uso doméstico está em torno de 1 st/família/mês, conforme levantamento feito com os assentados.

b) Pastagem natural: a pecuária extensiva, principalmente de caprinos, é uma das principais atividades econômicas dos assentados. Toda ela depende do suporte forrageiro das matas nativas. $\mathrm{O}$ desmatamento melhora o pasto a partir do momento em que aumenta a produção de gramíneas; no entanto, em épocas de estiagem prolongada, o que não é raro na região, áreas com cobertura florestal nativa, mesmo com menor suporte forrageiro, mantêm a produção animal mais estável (Campello et al., 1999).

c) Infra-estrutura: a madeira é utilizada na construção de casas, cercas dos lotes (estacas e mourões) e nos quintais das casas ("estacotes").

$\mathbf{Q}$ u adro 8 - E stoque geralpor classe de diâm etro para o tipo arbóreo fechado

Table 8 - $G$ eneral stock by diam eter class for den se a rboreal type

\begin{tabular}{|c|c|c|c|c|c|c|}
\hline \multirow{2}{*}{ Classe de Diâmetro } & \multirow{2}{*}{$\begin{array}{c}\text { Densidade } \\
\text { (arv./ha) }\end{array}$} & \multirow{2}{*}{$\begin{array}{c}\text { População } \\
(\%)\end{array}$} & \multirow{2}{*}{$\begin{array}{c}\text { Área Basal } \\
\left(\mathrm{m}^{2} / \mathrm{ha}\right)\end{array}$} & \multicolumn{3}{|c|}{ Volume } \\
\hline & & & & $\left(\mathrm{m}^{3} / \mathrm{ha}\right)$ & (st/ha) & $(\%)$ \\
\hline I & 4.833 & 82,86 & 5,75 & 43,28 & 147,18 & 39,80 \\
\hline II & 517 & 8,86 & 3,20 & 16,85 & 57,28 & 15,50 \\
\hline III & 142 & 2,43 & 1,52 & 7,57 & 25,72 & 6,96 \\
\hline IV & 125 & 2,15 & 1,78 & 10,76 & 36,57 & 9,90 \\
\hline $\mathrm{V}$ & 216 & 3,70 & 5,17 & 30,27 & 102,93 & 27,84 \\
\hline Total & 5.833 & 100,00 & 17,42 & 108,73 & 369,68 & 100,00 \\
\hline
\end{tabular}


$Q$ u adro 9 - F requiên cia das espécies en contradas no levantam ento florístico

Table $9-F$ requency of the species found in the floristic survey

\begin{tabular}{|c|c|c|c|c|c|}
\hline Espécie & Nome Científico & $\begin{array}{c}\text { Freqüência } \\
(\%)\end{array}$ & Espécie & Nome Científico & \begin{tabular}{|c|} 
Freqüência \\
$(\%)$
\end{tabular} \\
\hline Alecrim & Lantana microphylla Mart. & 4,4 & Jurema-branca & $\begin{array}{l}\text { Chloroleucon dumosum (Benth.) G.P. } \\
\text { Lewis }\end{array}$ & 64,0 \\
\hline Ameixa & Ximenia americana $\mathrm{L}$. & 11,0 & Jurema-de-imbira & Mimosa malacocentra Mart. ex Benth. & 60,0 \\
\hline Angico & Anadenanthera macrocarpa (Benth.) & 22,0 & Jurema-preta & Mimosa tenniflora (Willd.) Poir.. & 38,0 \\
\hline Aroeira & Myracrodruon urundeuva Allemão & 31,0 & Macambira & Bromelia laciniosa Mart. ex Schult. f. & 62,0 \\
\hline Bugi & Combretum laxum Jacq. & 49,0 & Malva & Malva sp. & 4,0 \\
\hline Café-bravo & Casearia sp. & 4,0 & Mandacaru & Cereus jamacaru DC. & 24,0 \\
\hline Câmara & Lantana camara $\mathrm{L}$. & 4,0 & Maniçoba & Manihot glaziovii Müll. Arg. & 27,0 \\
\hline Canela & Linharia aromatica Arruda ex Koster & 2,0 & Maria-preta & Cordia salzmanni DC. & 7,0 \\
\hline Canela-de-veado & Caesalpinia laxiflora Tul. & 7,0 & Marmeleiro & Croton hemiargyreus Müll. Arg. & 93,0 \\
\hline Capa-bode & Não-identificada & 7,0 & Mofumbo & Combretum leprosum Mart. & 69,0 \\
\hline Catanduba & Piptadenia moniliformis Benth. & 24,0 & Mororó & Bauhinia forficata Link & 75,0 \\
\hline Catingueira & Caesalpinia pyramidalis Tul. & 82,0 & Murici & Byrsonima crassifolia H.B.K. & 2,0 \\
\hline Caraíba & Tabebuia caraiba (Mart.) Bureau & 2,0 & Mutamba & Guazuma ulmifolia Lam. & 2,0 \\
\hline Cumaru & $\begin{array}{l}\text { Amburana cearensis (Allemão) A.C. } \\
\text { Sm. }\end{array}$ & 7,0 & Palmatória & Opuntia palmadora Britton \& Rose & 22,0 \\
\hline Espinheiro & Acacia piauhiensis Benth. & 2,0 & Pau-branco & Auxemma oncocalyx Baill. & 44,0 \\
\hline Facheiro & $\begin{array}{l}\text { Pilosocereus glauscescens (Labour.) } \\
\text { Byles \& Rowley }\end{array}$ & 18,0 & Pau-de-leite & Euphorbia phosphorea Mart. & 2,0 \\
\hline Feijão-bravo & Capparis cynophallophora L. & 18,0 & Pereiro & Aspidosperma pyrifolium Mart. & 51,0 \\
\hline Guaxumba & Urena lobata L. & 2,0 & Pinhão & Jatropha pohliana Müll. Arg. & 29,0 \\
\hline Imbiratanha & Bombax spp. & 15,0 & Pacotê & Cochlospernum insigne A. ST.-Hil. & 4,0 \\
\hline Imburana & $\begin{array}{l}\text { Commiphora leptophloeos (Mart.) } \\
\text { J.B. Gillett }\end{array}$ & 55,0 & Quixabeira & $\begin{array}{l}\text { Sideroxylon dotusifolium (Roem. \& } \\
\text { Schult.) T.D. Penn. }\end{array}$ & 7,0 \\
\hline Indeterminadas & & 16,0 & Sabiá & Mimosa caesalpiniaefolia Benth. & 24,0 \\
\hline João-mole & Guapira tomentosa (Casar.) Lundell & 35,0 & Velame & Croton campestris A. St.-Hil. & 7,0 \\
\hline Juazeiro & Ziziphus joazeiro Mart. & 2,0 & Xiquexique & $\begin{array}{l}\text { Pilosocereus gounellei (A. Weber ex } \\
\text { K. Schum.) Byles \& Rowley }\end{array}$ & 20,0 \\
\hline Jucá & Caesalpinia ferrea Mart. & 4,0 & & & \\
\hline
\end{tabular}

d) Medicina: o cumaru (Amburana cearensis), o juazeiro (Ziziphus joazeiro) e muitas outras espécies são tradicionalmente utilizados na fabricação de remédios caseiros.

Essas atividades são importantes no contexto social, sendo fundamental para a sustentabilidade dos assentamentos.

Para determinar o potencial de uso dos recursos florestais, foram consideradas as principais formas de exploração comercial e as espécies utilizadas, conforme informações coletadas com os assentados (Quadro 10). Na determinação do estoque de colheita sustentável (Quadro 11) foi considerado o incremento médio anual de $1,06 \mathrm{~m}^{3} /$ ha.ano, encontrado pelo programa PNUD/FAO/IBAMA (1993) para a região do Sertão Potiguar (para a tipologia 3), e o de $0,35 \mathrm{~m}^{3} /$ ha.ano (para a tipologia 2), conforme encontrado por Zákia et al. (1988) na região do Seridó.

A área explorável considerada foi obtida pelo somatório dos lotes individuais com a área coletiva de cada assentamento. $\mathrm{O}$ passo seguinte foi determinar a contribuição porcentual de cada modalidade de uso (lenha, carvão, estaca e mourão) sobre o estoque total, conforme informações citadas no Quadro 10. 
$Q$ uadro 10 - D etem inação do poten cialdas espécies por tipo de uso

Table $10-D$ eterm ination ofpotential of species based on type of use

\begin{tabular}{|c|c|c|}
\hline Tipo de Uso & Diâmetro $(\mathrm{cm})$ & \multicolumn{1}{c|}{ Espécies Exploradas } \\
\hline Estacas e mourões & $7-14$ & $\begin{array}{l}\text { Jurema-branca (Chloroleucon dumosum), jurema-de-imbira (Mimosa } \\
\text { malacocentra), jurema-preta (Mimosa tenniflora), mororó (Bauhinia forficata), } \\
\text { catingueira (Caesalpinia pyramidalis) e sabiá (Mimosa caesalpiniaefolia) }\end{array}$ \\
\hline Lenha e carvão & $>2$ & \begin{tabular}{l} 
Todas as espécies \\
\hline
\end{tabular}
\end{tabular}

Q u adro 11 - E stoque de colheita sustentáveldas m atas nativas de sete assentam entos do $\mathrm{R}$ io $\mathrm{G}$ rande do $\mathrm{N}$ orte

$T$ able 11 - Susta inable harvest stock of the native forest of seven settlem ent projects of the $R$ io $G$ rande do $N$ orte sta te

\begin{tabular}{|c|c|c|c|c|}
\hline \multirow{2}{*}{ PA } & Área Explorável & ${\text { Produção Sustentável }{ }^{1 /}}^{1 /}$ & Lenha e carvão & Estaca e mourões \\
\hline & (ha) & $\left(\mathrm{m}^{3} / \mathrm{ano}\right)$ & \multicolumn{2}{|c|}{$(\%)$} \\
\hline Aurora da Serra & $1.143,4$ & $1.212,00$ & 66 & 20 \\
\hline Cabelo de Negro & $2.263,2$ & $2.398,99$ & 55 & 16 \\
\hline Cordão de Sombra & $2.992,8$ & $3.172,37$ & 70 & 17 \\
\hline Lagoa Vermelha & 944,7 & $1.001,38$ & 72 & 4 \\
\hline Mulunguzinho & $3.162,7$ & $3.352,46$ & 49 & 13 \\
\hline Recreio & $1.611,4$ & $1.708,08$ & 80 & 6,4 \\
\hline Soledade & 777,0 & 823,09 & 80 & 10 \\
\hline Total & $9.902,4$ & $13.668,37$ & & \\
\hline
\end{tabular}

1/ Com base no incremento médio anual.

Nesse levantamento foram excluídas as espécies de aroeira e imburana. A primeira pelo fato de ser protegida por lei e a segunda, pela baixa freqüência encontrada. Foram excluídos também os PAs de Canto Comprido, por falta de dados, e os de Hipólito e Esperança, por apresentarem coberturas florestais do tipo 2, de baixa densidade e acentuada pobreza em termos de florística, sendo mais destinada a programas de enriquecimento. Nota-se o potencial de uso comercial elevado para essas matas, chegando a $90 \%$ no caso de Soledade. Com os valores apresentados no Quadro 11, foi possível determinar a provável contribuição que esse recurso poderia oferecer na geração de renda aos assentados. Para isto, consideraram-se os valores líquidos médios encontrados na comercialização da lenha na região, em $\mathrm{R} \$ 2,00 /$ st, não levando em conta o consumo doméstico, estimado em $1 \mathrm{st} / \mathrm{mês} /$ família. Para as estacas, esse valor está em $\mathrm{R} \$ 0,45 /$ un., em que $1 \mathrm{~m}^{3}$ corresponde a cerca de 102 estacas (Carvalho, 1998) (Quadro 12).

Os valores obtidos na determinação do potencial econômico da comercialização de produtos florestais (Quadro 12) foram relativamente baixos, mas provavelmente, com manejo adequado, poderão ser incrementados
Q uadro 12 - D eterm inação do potencial econôm ico da co$\mathrm{m}$ ercialização de produtos florestais

Table 12 - Determ ination of the econom ic potential for com $m$ ercialization of forest products

\begin{tabular}{|l|c|c|c|}
\hline \multirow{2}{*}{\multicolumn{1}{|c|}{ PA }} & \multicolumn{2}{|c|}{ Quantidade } & \multirow{2}{*}{ Renda/mês } \\
\cline { 2 - 3 } & Lenha & $\begin{array}{c}\text { Estaca e } \\
\text { mourão }\end{array}$ & \\
\cline { 2 - 3 } & (st) & (unidade) & \multicolumn{1}{c|}{ (R\$) } \\
\hline Aurora da Serra & $2.719,7$ & 24.725 & $1.264,47$ \\
Cabelo de Negro & $4.486,1$ & 39.152 & $2.023,87$ \\
Cordão de Sombra & $7.550,2$ & 55.009 & $3.087,20$ \\
Lagoa Vermelha & $2.451,4$ & 4.086 & 493,78 \\
Mulunguzinho & $5.585,2$ & 44.454 & $2.373,88$ \\
Recreio & $4.646,0$ & 11.150 & $1.046,47$ \\
Soledade & $2.238,8$ & 8.396 & 619,97 \\
\hline
\end{tabular}

consideravelmente. Carvalho (1998) determinou um valor de $\mathrm{R} \$ 5.833,00 /$ mês caso fosse aplicado o "Plano de Manejo Florestal do assentamento Canto Comprido". Ainda assim, considerando o número total de famílias de cada PA, essa quantia seria substancialmente reduzida. Essa atividade deve ser uma alternativa de renda, principalmente para aqueles assentados que não estão

R. Árvore, Viçosa-MG, v.27, n.1, p.79-86, 2003 
engajados em outras atividades geradoras de renda dentro do assentamento.

O tamanho médio dos módulos encontrado, em torno de 33 ha/família, permite, por exemplo, a criação de cerca de 16 caprinos, considerando o suporte de 1,5 a 2,0 ha para cada animal ao ano, determinado por Brasil (1998) para a caatinga nativa, e muitas vezes o assentado possui número muito maior de animais. As condições de semiaridez devem ser um fator relevante no momento de definir o tamanho dos lotes individuais nos assentamentos. Considerando apenas a rentabilidade na exploração da mata nativa do tipo 3 , sem aplicação de nenhum tipo de manejo especial, para um potencial de uso comercial médio das áreas inventariadas de $67 \%$ para lenha e carvão e $12 \%$ para estacas e mourões, o tamanho da área explorada por cada família, a fim de obter rendimento de um salário mínimo mensal, teria de ser de em torno de 170 ha para a região estudada. Devido à sua baixa rentabilidade, essa atividade deveria ser apenas um complemento de renda, já que outras atividades apresentam maiores rendimentos, como pode ser verificado no Quadro 13, onde foi considerada a renda média mensal por família de três assentamentos. O primeiro, Cabelo de Negro, não possui fonte própria de água e tem como principal atividade econômica o extrativismo florestal. Os dois seguintes, Hipólito e Soledade, produzem melão para exportação. Os valores foram baseados nos volumes totais comercializados, e o seu preço médio foi deduzido dos custos de produção.

\section{CONCLUSÕES}

As espécies mais bem distribuídas pelas unidades amostrais foram justamente as de caráter pioneiro, o que indica que essas matas já foram exploradas anteriormente à ocupação dos assentados. $\mathrm{O}$ estrato florestal mais comum foi o arbustivo-arbóreo fechado. Os assentamentos

Quadro 13 - Renda m édia m ensal das principais atividades econôm icas de três assentam entos do $\mathrm{R}$ io $\mathrm{G}$ rande do $\mathrm{N}$ orte

Table 13 - $M$ onthly average incom e provided by the $m$ ain econom ic activities of three settlem ent projects in the $R$ io state of $G$ rande do $N$ orte

\begin{tabular}{|l|l|c|c|}
\hline \multicolumn{1}{|c|}{ PA } & \multicolumn{1}{c|}{$\begin{array}{c}\text { Principal Atividade } \\
\text { Econômica }\end{array}$} & $\begin{array}{c}\mathrm{N}^{\mathrm{o}} \text { de } \\
\text { Famílias }\end{array}$ & $\begin{array}{c}\text { Renda/Famí- } \\
\text { lia/Mês (R\$) }\end{array}$ \\
\hline Cabelo de Negro & Extrativismo florestal & 96 & 36,00 \\
Hipólito & Fruticultura irrigada & 44 & 177,00 \\
Soledade & Fruticultura irrigada & 33 & 216,00 \\
\hline
\end{tabular}

com presença de cobertura florestal do tipo arbustivoarbórea aberta (tipo 2) apresentam baixa densidade, associada à baixa diversidade florística e à forte tendência à homogeneização, o que as enquadra como prioritárias em um processo de conservação e, ou, enriquecimento da flora. Devido à baixa rentabilidade da exploração dos recursos florestais da caatinga, essa atividade deveria servir apenas como complemento de renda dos assentados, uma vez que outras atividades apresentam maiores retornos econômicos. Entretanto, ela possui grande importância no contexto social, sendo fundamental para manutenção dos assentamentos que não possuem infraestrutura produtiva (irrigação).

\section{REFERÊNCIAS BIBLIOGRÁFICAS}

AB'SABER, A. N. Sertões e sertanejos: uma geografia humana sofrida. Revista Estudos Avançados, v. 13, n. 36, p. $72-83,1999$.

BRASIL. Ministério do Meio Ambiente - MMA. Instituto Brasileiro do Meio Ambiente e dos Recursos Renováveis IBAMA. Instrução normativa $n^{\circ} 1 / 98$ de 06 de outubro de 1998.

CAMPELLO, F. B. et al. Diagnóstico florestal da região Nordeste. Brasília: IBAMA; PNUD, 1999. 20 p.

CARVALHO, A. J. E. Plano de manejo florestal assentamento Canto Comprido - Carnaubais - RN. Natal: [s.n.], 1998. 23 p.

CARVAlHO, A. J. E.; ZÁKIA, M. J. B. Avaliação do estoque madeireiro: etapa final - inventário Florestal do Estado do Rio Grande do Norte. Natal: IBAMA, 1994. 84 p. (Projeto PNUD/FAO/IBAMA/ GOVERNO DO RIO GRANDE DO NORTE; Documento de Campo, 13).

INSTITUTO BRASILEIRO DO MEIO AMBIENTE E DOS RECURSOS RENOVÁVEIS - IBAMA. Programa nacional de conservação e desenvolvimento florestal sustentável. Brasília, 1991. 80 p.

INSTITUTO NACIONAL DE COLONIZAÇÃO E REFORMA AGRÁRIA - INCRA. Dados sobre a reforma agrária no Brasil. Brasília: 1999.

OLIVEIRA, R.D.; OLIVEIRA, M. D. Pesquisa social educativa: conhecer a realidade para poder transformá-la. In: BRANDÃO, C.R. Pesquisa participante. 2.ed. São Paulo: 1982.

PNUD; FAO; IBAMA. Diagnóstico florestal do Rio Grande do Norte. Natal: [s.n.], 1993. 45 p. 